\title{
(6) OPEN ACCESS \\ High prevalence of infection and low incidence of disease in child contacts of patients with drug- resistant tuberculosis: a prospective cohort study
}

\author{
Helena Huerga, ${ }^{1}$ Elisabeth Sanchez-Padilla, ${ }^{1}$ Nara Melikyan, ${ }^{1}$ Hakob Atshemyan, ${ }^{2}$ \\ Armen Hayrapetyan, ${ }^{3}$ Ani Ulumyan, ${ }^{4}$ Mathieu Bastard, ${ }^{1}$ Naira Khachatryan, ${ }^{2}$ \\ Catherine Hewison, ${ }^{5}$ Francis Varaine, ${ }^{5}$ Maryline Bonnet ${ }^{1,6}$
}

Received 26 April 2018 Revised 15 November 2018 Accepted 16 November 2018 Published Online First

6 December 2018 incident disease were diagnosed during follow-up. After adjustment, prevalent LTBI was significantly associated with the child's age, sleeping in the same house, higher household density, the index case's age, positive smear result and presence of lung cavities.

Conclusions Children in close contact with patients with DR-TB or in contact with very contagious patients had an increased risk of prevalent LTBI. Although none of the children developed TB disease during a 2-year follow-up period, screening for symptoms of TB disease, based on the prevalence of disease at recruitment, together with follow-up and repeated testing of noninfected contacts, is highly recommended in paediatric contacts of patients with DR-TB.

- http://dx.doi.org/10.1136/ archdischild-2018-315453

Check for updates

(C) Author(s) (or their employer(s)) 2019. Re-use permitted under CC BY-NC. No commercial re-use. See rights and permissions. Published by BMJ.

To cite: Huerga H, SanchezPadilla E, Melikyan N, et al. Arch Dis Child

2019:104:622-628.

\section{BACKGROUND}

Mycobacterium tuberculosis bacilli (MTB) are transmitted almost exclusively from person to person via shared air. Children in close contact with patients with respiratory tuberculosis (TB) are at high risk of acquiring latent TB infection (LTBI) and are at high risk of progressing from LTBI to the disease. Contact tracing to promptly identify infected and diseased contacts is crucial for TB control. ${ }^{1}$ The worldwide occurrence of drug resistance is threatening the global eradication of TB. moderate TB disease rates at baseline (2\%).

- Children with no evidence of latent TB infection (LTBI) at baseline developed LTBI during the 2 years of follow-up at a rate of 20/100 children per year.

- Despite the absence of preventive treatment none of the children developed TB disease during the 2 years of follow-up.

Recent molecular epidemiological studies suggest that recent transmission, rather than acquisition of resistance, is driving the drug-resistant TB (DR-TB) epidemic. $^{2}$ This depends not solely on the relative fitness value of the strain but also on environmental factors such as TB control policies, time to diagnosis and treatment, and case finding rates. ${ }^{34}$

Therefore, more epidemiological evidence is needed on the risk of infection and disease among contacts of patients with DR-TB in endemic settings, especially among populations at high risk, such as children, in order to guide future policy development for screening and preventive therapy. Previous studies have measured the prevalence of LTBI and TB disease among child household contacts of patients with DR-TB, ${ }^{5-11}$ but have rarely conducted a contact investigation prospectively. ${ }^{57}$ We aimed to measure the prevalence and incidence of LTBI and 
TB disease in children in close contact with adult patients with DR-TB in Armenia, a country with a high DR-TB prevalence.

\section{MATERIALS AND METHODS}

Study design and population

A prospective study was conducted in Yerevan and the marzes (districts) supported by Médecins Sans Frontiéres-Armavir, Shirak, Lori, Kotayk, Ararat and Gegharkunik-which include $85 \%$ of the country's population and $96 \%$ of all patients diagnosed with DR-TB. The incidence of TB in Armenia was 44 cases per 100000 in 2016 (95\% CI 34 to 56), with 11\% of new TB cases and $47 \%$ of previously treated TB cases being rifampicin-resistant or multidrug-resistant TB (MDR-TB; resistant to rifampicin and isoniazid). ${ }^{12}$

Consecutive newly diagnosed index cases (defined as patients 15 years old or older, with a sputum culture or Xpert MTB/RIF assay positive for $M T B$, and infected with a strain resistant to isoniazid and/or rifampicin) were interviewed by the study nurse during the routine visits performed at home or at the hospital to identify contacts. A paediatric contact was defined as a child $<15$ years old living in the household of the index case or who had more than 7 days of contact for at least 4 hours per day during the 6 months prior to the index case registration.

\section{Study procedures}

Children underwent an initial detailed clinical assessment, an anteroposterior chest X-ray (CXR) (left lateral views were performed when anteroposterior view was insufficient for interpretation), a tuberculin skin test (TST) (5TU purified protein derivative; Tubersol, Sanofi Pasteur) and interferon-gamma release assay testing (IGRA) (QuantiFERON-TB Gold In-Tube; Cellestis). HIV testing was offered to symptomatic contacts and to contacts of known HIV-infected index cases. Children were examined clinically every 3 months for a period of 24 months. In initially non-infected contacts, TST and IGRA were repeated on the second visit and 3 months after culture conversion of the index case. In addition, TST, IGRA and CXR were repeated if signs or symptoms suggestive of TB appeared, and routinely during follow-up at 12 and 24 months. In all children, CXR was repeated every 6 months, or if IGRA or TST conversion had occurred.

TST was independently read by the study's doctor and nurse; discordances were resolved by a separate clinic TB doctor. IGRA assays were quality-controlled every 6 months by the Immunology Quality Services of the UK National External Quality Assessment Service. CXRs were independently read by an experienced radiologist and the study doctor. A specific itemised CXR evaluation sheet was used to assess the quality and report the findings. ${ }^{13}$ Children with presumptive TB disease based on clinical or radiological findings were referred for further investigation with the support of study staff. This included the collection of at least two specimens for microbiological examination, either spontaneous sputum, when possible, or induced sputum, laryngopharyngeal or gastric aspiration, or stool samples.

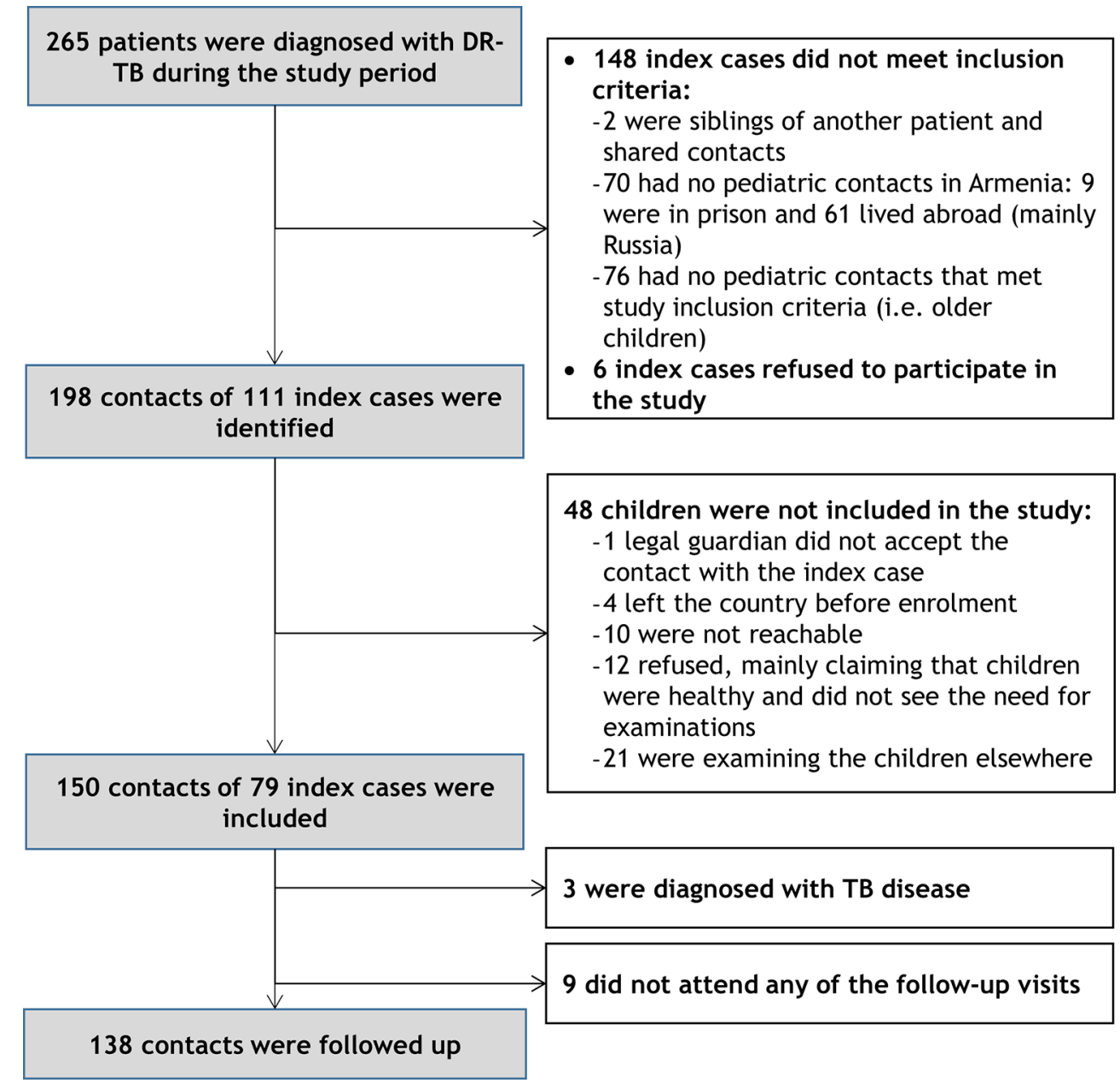

Figure 1 Study response rate and inclusion flow. DR-TB, drug-resistant tuberculosis. 
Asymptomatic contacts with a negative TST result $(<10 \mathrm{~mm}$ induration or $<5 \mathrm{~mm}$ if malnourished or HIV-infected), a negative IGRA result and normal CXR were classified as uninfected. Asymptomatic contacts with either a positive TST or IGRA test result and a normal CXR were classified as LTBI. Children with TB disease were classified as confirmed TB (at least one positive culture/Xpert for MTB), probable TB (suggestive symptoms and CXR consistent with intrathoracic $\mathrm{TB}$ disease) or possible $\mathrm{TB}$ (suggestive symptoms or CXR consistent with intrathoracic TB disease) ${ }^{14}$

\section{Statistical analysis}

Variables regarding sociodemographic factors, clinical signs and symptoms, microbiological information, vaccinations, previous exposure to patients with TB, and type and intensity of contact were obtained for index cases and contacts, and double-entered into the EpiData V.3.1 software (EpiData, Odense, Denmark). The prevalence of TB disease was calculated by dividing the number of contacts diagnosed with TB by the number of contacts screened. The prevalence of LTBI was calculated by dividing the number of contacts with a TST and/or IGRA positive result by the number of contacts with a result for both tests available, excluding children diagnosed with TB disease. Contacts with only a TST or IGRA result were excluded to avoid the risk of underestimating or overestimating the prevalence of infection. The incidence rates were calculated by dividing the number of children with incident LTBI by the total number of personyears of follow-up of non-infected contacts. For contacts lost to follow-up or diagnosed with LTBI between two follow-up visits, we assumed that the child had been at risk half of the time since the last visit was recorded. We calculated the CIs for the prevalence and incidence of LTBI and TB disease to get a range within which the true value in the population lies. The density of people in the household was calculated by dividing the number of people by the number of rooms in the household. When it was not approriate to treat them as linear, continuous variables were categorised using the LOWESS (locally weighted scatter-plot smoothing) plot of the marginal residuals to determine cutpoints. ${ }^{15}$ ORs and 95\% CIs were calculated to measure the degree of association between independent variables and LTBI at the initial evaluation. Variables with $\mathrm{p}<0.2$ on univariable analysis, or those which were considered epidemiologically or clinically relevant, were included in the multivariable analysis model. As some children had missing infection status after the first evaluation, we performed additional sensitivity and multiple imputation analyses (presented in the online supplementary file) to assess the effect of this in the estimation of the ORs. We used an alpha level of 5\% for all statistical tests. Analyses were performed using STATA V.13.

\section{RESULTS}

Characteristics of the study population

The study was conducted from June 2012 to December 2016. Of the 265 DR-TB index cases registered, 111 (41.9\%) reported having been in contact with 198 children who met the study inclusion criteria, of whom 150 children (75.8\%), contacts of 79 index cases, were included (figure 1). The 48 contacts not included were similar to those included in terms of age $(p=0.3201)$, gender $(p=0.9136)$, relationship to contact $(p=0.1382)$, number of household contacts $(p=0.450)$, and their respective index cases' age $(p=0.6593)$ and sputum smear result $(p=0.1406)$. The median number of paediatric contacts per index case reporting contact with children was 2 (IQR: 1-2).
The median age of the index cases was 37 years (IQR: 29-48), 62 (74.5\%) were male and 27 (34.2\%) lived in Yerevan. Of the 79 index cases, 28 (35.9\%) had previously received anti-TB treatment, including 3 who had treatment for DR-TB, 26 (32.9\%) were smear-negative, and 69 (88.5\%) had lung cavities on CXR. A total of 54 (68.4\%) cases had MDR-TB, 5 of which had extensively drug-resistant $\mathrm{TB}-\mathrm{MDR}-\mathrm{TB}$ in addition to resistance to any fluoroquinolone and at least one of three injectable secondline drugs. The characteristics of the 150 contacts included in the study are shown in table 1 . The three children who were tested for HIV infection had negative test results.

\section{Prevalence and incidence of TB disease and LTBI}

In our study, of 150 children, 3 were diagnosed with TB disease at baseline, suggesting a prevalence in the wider population of 2.0\% (95\% CI 0.7 to 5.7): 3.3\% (95\% CI 0.9 to 11.4 ) in children

Table 1 Characteristics of paediatric contacts of patients with drugresistant TB $(n=150)$

\begin{tabular}{|c|c|}
\hline Characteristics & n (\%) \\
\hline Age (median in years, IQR) & $6(3-10)$ \\
\hline \multicolumn{2}{|l|}{ Age groups (years) } \\
\hline$<2$ & $24(16.0)$ \\
\hline $2-4$ & $36(24.0)$ \\
\hline$>5$ & $90(60.0)$ \\
\hline \multicolumn{2}{|l|}{ Gender } \\
\hline Male & $70(46.7)$ \\
\hline Female & $80(53.3)$ \\
\hline \multicolumn{2}{|l|}{ Nutrition status } \\
\hline Adequate & $144(96.0)$ \\
\hline Stunting* & $5(3.3)$ \\
\hline Wasting $\dagger$ & $1(0.7)$ \\
\hline Previous treatment for active TB received & $0(0.0)$ \\
\hline Previous isoniazid preventive treatment received & $7(4.7)$ \\
\hline BCG-vaccinated & $149(99.3)$ \\
\hline BCG scar present & $76(51.0)$ \\
\hline Comorbidities $¥$ & $4(2.7)$ \\
\hline \multicolumn{2}{|l|}{ Living conditions (median, IQR) } \\
\hline Number of people living in the same house & $5(4-7)$ \\
\hline Number of rooms in the house & $3(2-4)$ \\
\hline Number of bedrooms in the house & $2(2-3)$ \\
\hline \multicolumn{2}{|l|}{ Exposure to smoke } \\
\hline Child who smokes cigarettes & $1(0.7)$ \\
\hline Child exposed to cigarette smoke & $114(76.0)$ \\
\hline $\begin{array}{l}\text { Child exposed to other types of household smoke (eg, wood } \\
\text { burner) }\end{array}$ & $71(47.3)$ \\
\hline Sleeps in the same house as index case & $118(78.7)$ \\
\hline Sleeps in the same room as index case & $41(34.8)$ \\
\hline Daily contact with the index case & $123(82.0)$ \\
\hline Number of hours of exposure per week (median, IQR) & $42(14-84)$ \\
\hline Sibling or infant of the index case & $84(56.0)$ \\
\hline Known exposure to an additional patient with TB & $5(3.3)$ \\
\hline \multicolumn{2}{|l|}{ Place of residence } \\
\hline Yerevan city & $46(30.7)$ \\
\hline Other regions & $104(69.3)$ \\
\hline
\end{tabular}

*Stunting: height for age $<-2$ SD of the WHO Child Growth Standards median. tWasting: weight for height $<-2$ SD of the WHO Child Growth Standards median for children up to 5 years.

$\ddagger$ Comorbidities: one vesicoureteral reflux, one aortic valve stenosis, one Down's syndrome and one developmental delay.

$B C G$, bacille Clmette-Guerin; IQR, interquartile range; TB, tuberculosis. 
Table 2 Prevalence of LTBI, positive TST and positive IGRA tests by age group

\begin{tabular}{|c|c|c|c|c|c|c|c|c|c|}
\hline \multirow[b]{2}{*}{ Age group (years) } & \multicolumn{3}{|c|}{ LTBI* } & \multicolumn{3}{|c|}{ Positive TST } & \multicolumn{3}{|c|}{ Positive IGRA } \\
\hline & $\mathrm{n}$ & $\%$ & $95 \% \mathrm{Cl}$ & $\mathbf{n}$ & $\%$ & $95 \% \mathrm{Cl}$ & $\mathrm{n}$ & $\%$ & $95 \% \mathrm{Cl}$ \\
\hline$<2$ & 11 & 45.5 & 16.7 to 76.6 & 20 & 45.0 & 25.8 to 65.8 & 12 & 41.7 & 19.3 to 68.0 \\
\hline $2-4$ & 23 & 47.8 & 26.8 to 69.4 & 33 & 42.4 & 27.2 to 59.2 & 20 & 55.0 & 34.2 to 74.2 \\
\hline$\leq 5$ & 34 & 47.1 & 29.8 to 64.9 & 53 & 43.4 & 31.0 to 56.7 & 32 & 50.0 & 33.6 to 66.4 \\
\hline$>5$ & 75 & 64.0 & 52.1 to 74.8 & 79 & 59.5 & 48.5 to 65.6 & 78 & 52.6 & 41.6 to 62.3 \\
\hline Overall & 109 & 58.7 & 48.9 to 68.1 & 132 & 53.0 & 44.6 to 61.3 & 110 & 51.8 & 42.6 to 60.9 \\
\hline
\end{tabular}

*Only children with valid results for TST and IGRA were included (indeterminate results for IGRA have been excluded).

IGRA, interferon-gamma release assay; LTBI, latent TB infection; TB, tuberculosis; TST, tuberculin skin test

$<5$ years old and $1.1 \%$ (95\% CI 0.2 to 6.0$)$ in children $>5$ years old. In children $<2$ years old the prevalence was $8.3 \%(95 \% \mathrm{CI}$ 2.3 to 25.8 ) and was significantly higher than for the $\geq 2$ group (0.8\%; 95\% CI 0.1 to 4.4 ) (Pearson's $\left.\mathrm{X}^{2} \mathrm{p}=0.016\right)$. TB disease was confirmed by culture on bronchial fluid in a 7 -month-old child, and two asymptomatic children were diagnosed with possible TB based on CXR findings.

On the first examination, 109 children had valid TST and IGRA results (indeterminate results excluded). The prevalence of LTBI was $58.7 \%$ (95\% CI 48.9 to 68.1 ). Table 2 shows the prevalence of LTBI and the proportions of positive TST and positive IGRA by age group. Indeterminate IGRA results were more frequent in children aged less than 5 years compared with the older group $(8.6 \%$ vs $1.3 \%, \mathrm{p}=0.051)$. In addition, children less than 5 years had an IGRA tests done less frequently $(58.3 \%$ vs $87.8 \%, \mathrm{p}<0.001)$ due to the difficulties in drawing blood in the younger age group $(6.7 \%$ vs $1.1 \%, p=0.0647)$ and the higher proportion of legal guardians who refused blood tests $(30.0 \%$ vs $10.0 \%, \mathrm{p}=0.0018)$. Similar proportions of TST results were available in both age groups $(88.3 \%$ vs $92.9 \%$, $\mathrm{p}=0.339)$.

Of the 147 children without TB disease at baseline, 138 (94.0\%) attended at least one follow-up visit, of whom 133 (96.4\%) were followed for at least 1 year and $123(89.1 \%)$ for 2 years. The median number of evaluations per child was 9 (IQR: 9-9). During the follow-up, an additional 11 children were diagnosed with incident LTBI, of whom 5 were diagnosed during the first 3 months of the follow-up period. The incidence rate of LTBI was 19.9 per 100 children-years (95\% CI 11.0 to 35.9) (table 3). No additional incident TB disease was diagnosed during follow-up.

Table 3 Incidence rate of latent tuberculosis infection per 100 children per year by age group and year of follow-up among the 40 children not infected at baseline and followed-up

\begin{tabular}{llll}
\hline & Newly infected & Incidence rate & $95 \% \mathrm{Cl}$ \\
\hline Age group (years) & & & \\
\hline$<2$ & 2 & 19.4 & 4.9 to 77.8 \\
\hline $2-4$ & 3 & 22.4 & 7.2 to 69.5 \\
\hline 5 & 5 & 21.1 & 8.8 to 50.8 \\
\hline$>5$ & 6 & 18.9 & 8.5 to 42.1 \\
\hline Time of follow-up & & & \\
\hline First 3 months & 5 & 53.4 & 22.2 to 128.4 \\
\hline First 6 months & 6 & 33.3 & 15.0 to 74.1 \\
\hline First year & 8 & 24.2 & 12.1 to 48.4 \\
\hline Second year & 3 & 13.8 & 4.4 to 42.7 \\
\hline Overall & 11 & 19.9 & 11.0 to 35.9 \\
\hline
\end{tabular}

\section{Factors associated with prevalent LTBI}

The univariable and multivariable logistic regression analyses for predictive variables of LTBI are shown in tables 4 and 5 . After adjustment, prevalent LTBI was significantly associated with child age, sleeping in the same house, higher household density and index case age, smear result and lung cavities on CXR. In addition, the interaction between contact age and the presence of lung cavities was within the limit of statistical significance. Although older age of contact remained associated with paediatric prevalent LTBI for index cases without cavities, the association was no longer seen for index cases with lung cavities (figure 2). Similarly, the odds of LTBI in contacts of patients with lung cavities were significantly higher only in children $<5$ years. None of the variables collected on the characteristics of the caregivers (ie, sociodemographic factors) were associated with prevalent LTBI (data not shown). The results of the additional analyses to assess the effect of missing values were consistent with the main analysis (online supplementary file).

\section{DISCUSSION}

This prospective cohort study, including almost the entire population of patients diagnosed with DR-TB in Armenia during the study period, found a high prevalence of LTBI among paediatric contacts at baseline and a moderate incidence during the 24 months' follow-up. Although three children were diagnosed with TB disease at baseline, none developed the disease during follow-up.

The prevalence of TB disease in our cohort was similar to that reported from other countries, ${ }^{78} 11$ but lower than that previously reported in South African children $<5$ years $(11.2 \%$ and $6.6 \%) .{ }^{59}$ In addition, the absence of TB disease during follow-up in our study differs from the studies in South Africa, despite the use of preventive treatment in that setting. ${ }^{56}$ These findings may be explained by various factors. Malnutrition and HIV infection are well known to contribute to TB progression. ${ }^{9}{ }^{16-18}$ In our cohort, malnutrition was not frequent and a low prevalence of HIV infection is likely since the prevalence of HIV in adults in Armenia is only $0.2 \% .{ }^{19}$ In addition the highest risk of disease progression after infection was observed in children $<2$ years, who represented only $14 \%$ of our cohort. ${ }^{20}$ It has also been suggested that DR-TB strains may be more infectious but less virulent than drug-susceptible TB strains, with infected contacts being less likely to develop active $\mathrm{TB}$, although this premise remains controversial. ${ }^{11}$ 21-25

Studies in different settings have observed prevalences of LTBI in similar populations ranging from $38 \%$ to $76 \% .^{571011}$ The age of the children included may affect the prevalence observed, as the risk of LTBI increases with age, likely as a result of repeated exposures over time. ${ }^{9}$ Variations in study results of the estimated prevalence of LTBI may be related to IGRA use (thought to be 
Table 4 Univariable logistic regression analysis for predictive variables of LTBI $(n=109)$.

\begin{tabular}{|c|c|c|c|c|c|}
\hline & $\begin{array}{l}\text { Infectec } \\
\text { Total }\end{array}$ & $\%$ & $\mathrm{OR}$ & $95 \% \mathrm{Cl}$ & $P$ values \\
\hline \multicolumn{6}{|l|}{ Gender } \\
\hline Male & $29 / 51$ & 56.9 & Ref & & \\
\hline Female & $35 / 58$ & 60.3 & 1.15 & 0.54 to 2.48 & 0.713 \\
\hline \multicolumn{6}{|c|}{ Age $^{*}$ (years) } \\
\hline$<5$ & $16 / 34$ & 47.1 & Ref & & \\
\hline$\geq 5$ & $48 / 75$ & 64.0 & 2.00 & 0.88 to 4.55 & 0.098 \\
\hline \multicolumn{6}{|c|}{ District where the contact lives } \\
\hline Yerevan & $19 / 31$ & 61.3 & 1.16 & 0.50 to 2.72 & 0.731 \\
\hline Other & $45 / 78$ & 57.7 & Ref & & \\
\hline \multicolumn{6}{|c|}{ BCG vaccination scar } \\
\hline No & $35 / 62$ & 56.5 & Ref & & \\
\hline Yes & $29 / 47$ & 61.7 & 1.24 & 0.57 to 2.69 & 0.582 \\
\hline \multicolumn{6}{|c|}{ Number of rooms in the householdt } \\
\hline$\leq 4$ & $61 / 93$ & 65.6 & 7.87 & 2.07 to 29.97 & 0.002 \\
\hline$>4$ & $3 / 16$ & 18.8 & Ref & & \\
\hline
\end{tabular}

Number of bedrooms

\begin{tabular}{|c|c|c|c|c|c|}
\hline$\leq 3$ & $59 / 103$ & 57.3 & Ref & & \\
\hline$>3$ & $5 / 6$ & 83.3 & 3.73 & 0.42 to 33.06 & 0.237 \\
\hline \multicolumn{6}{|c|}{ Number of people in the household } \\
\hline$\leq 7$ & $54 / 97$ & 55.7 & Ref & & \\
\hline$>7$ & $10 / 12$ & 83.3 & 3.98 & 0.83 to 19.14 & 0.085 \\
\hline \multicolumn{6}{|l|}{ Household density§ } \\
\hline $\begin{array}{l}<1.5 \text { person per } \\
\text { room }\end{array}$ & $15 / 37$ & 40.5 & Ref & & \\
\hline $\begin{array}{l}\geq 1.5 \text { person per } \\
\text { room }\end{array}$ & $49 / 72$ & 68.1 & 3.12 & 1.37 to 7.11 & 0.007 \\
\hline \multicolumn{6}{|c|}{ Sleeps in same house as index case } \\
\hline No & 9/24 & 37.5 & Ref & & \\
\hline Yes & $55 / 85$ & 64.7 & 3.06 & 1.20 to 7.81 & 0.020 \\
\hline
\end{tabular}

Sleeps in same room as index case

\begin{tabular}{|c|c|c|c|c|c|}
\hline No & $45 / 78$ & 57.7 & Ref & & \\
\hline Yes & $19 / 31$ & 61.3 & 1.16 & 0.50 to 2.72 & 0.731 \\
\hline \multicolumn{6}{|c|}{ Relationship with index case } \\
\hline Infant or sibling & $46 / 65$ & 70.8 & 3.50 & 1.56 to 7.82 & 0.002 \\
\hline Other & $18 / 44$ & 40.9 & Ref & & \\
\hline \multicolumn{6}{|c|}{ Daily exposure to index case } \\
\hline No & $7 / 17$ & 41.2 & Ref & & \\
\hline Yes & $57 / 92$ & 62.0 & 2.33 & 0.81 to 6.67 & 0.116 \\
\hline \multicolumn{6}{|l|}{ TST done previously } \\
\hline No & $21 / 51$ & 41.2 & & & \\
\hline Yes & $43 / 58$ & 74.1 & 4.10 & 1.82 to 9.21 & 0.001 \\
\hline \multicolumn{6}{|c|}{ Index case ageף (years) } \\
\hline$<30$ & $7 / 21$ & 33.3 & 0.12 & 0.04 to 0.37 & $<0.001$ \\
\hline $30-50$ & $46 / 57$ & 80.7 & Ref & & \\
\hline$>50$ & $11 / 31$ & 35.5 & 0.13 & 0.05 to 0.35 & $<0.001$ \\
\hline \multicolumn{6}{|c|}{ Index case smear result** } \\
\hline Negative & $14 / 39$ & 35.9 & Ref & & \\
\hline$<++$ & $13 / 19$ & 68.4 & 3.87 & 1.20 to 12.44 & 0.023 \\
\hline$++/+++$ & $37 / 51$ & 72.5 & 4.72 & 1.92 to 11.58 & 0.001 \\
\hline \multicolumn{6}{|c|}{ Index case with lung cavities } \\
\hline No & $5 / 14$ & 35.7 & Ref & & \\
\hline Yes & $59 / 95$ & 62.1 & 2.95 & 0.92 to 9.50 & 0.070 \\
\hline \multicolumn{6}{|c|}{ Index case with cough } \\
\hline No & $11 / 22$ & 50.0 & Ref & & \\
\hline Yes & $53 / 87$ & 60.9 & 1.56 & 0.61 to 3.99 & 0.355 \\
\hline
\end{tabular}

Continued
Table 4 Continued

\begin{tabular}{|c|c|c|c|c|c|}
\hline & $\begin{array}{l}\text { Infected } \\
\text { Total }\end{array}$ & $\%$ & OR & $95 \% \mathrm{Cl}$ & $P$ values \\
\hline \multicolumn{6}{|c|}{ Index case previously treated for TB } \\
\hline Yes & $15 / 35$ & 42.9 & Ref & & \\
\hline No & $49 / 74$ & 66.2 & 2.61 & 1.15 to 5.96 & 0.022 \\
\hline \multicolumn{6}{|c|}{ Index case resistance pattern } \\
\hline None to MDR & $18 / 31$ & 58.1 & & & \\
\hline MDR & $45 / 75$ & 60.0 & 1.08 & 0.46 to 2.53 & 0.854 \\
\hline \multicolumn{6}{|c|}{ Child exposed to other TB cases } \\
\hline No & $59 / 103$ & 57.3 & Ref & & \\
\hline Yes & $5 / 6$ & 83.3 & 3.73 & 0.42 to 33.06 & 0.237 \\
\hline
\end{tabular}

OR; Unadjusted $O R$.

p-values $<0.005$ in bold.

${ }^{*} P$ for trend: $0.111 ; \uparrow p$ trend: $0.149 ; \neq p$ trend: $0.932 ; \S p$ trend: $0.430 ;$ Ip trend: $0.101 ;{ }^{* *} p$ trend: 0.001

BCG, bacille calmette- Guerin; LTBI, latent TB infection; MDR, multidrug-resistant; ref, reference; TB, tuberculosis; TST, tuberculin skin test.

more specific than TST in BCG-immunised populations, but only used in a few studies) ${ }^{10}$ and the use of varying TST cut-offs (ie, $5 \mathrm{~mm}, 10 \mathrm{~mm}$ or $15 \mathrm{~mm}$ ). The TST positivity rate in our cohort would vary from $33.3 \%$ (95\% CI 25.4 to 42.1 ) to $65.2 \%$ (95\% CI 56.4 to 73.2 ) if the cut-offs were set to $15 \mathrm{~mm}$ and $5 \mathrm{~mm}$, respectively. An additional factor that may affect the estimated LTBI prevalence is the time to TST positivity, which can take up to 3 months. In our cohort, five children converted before the 12 -week visit, and including them as prevalent LTBI cases would increase the prevalence of LTBI to $63.3 \%$ (95\% CI 53.5 to 72.3 ).

In the absence of a standard definition of close contact, most studies only include household contacts. We additionally considered different aspects of the contact such as type, intensity and relationship. Indeed, we observed a higher risk of infection

Table 5 Multivariable logistic regression analysis for predictive variables of $L T B I(n=109)$.

\begin{tabular}{|c|c|c|c|}
\hline & aOR & $95 \% \mathrm{Cl}$ & $P$ values \\
\hline$>1.5$ persons per household room & 4.87 & 1.44 to 16.45 & 0.011 \\
\hline \multicolumn{4}{|l|}{ Index case $<50$ years old } \\
\hline$<30$ years & 0.17 & 0.03 to 0.83 & 0.029 \\
\hline $30-50$ years & Ref & & \\
\hline$>50$ years & 0.17 & 0.05 to 0.61 & 0.006 \\
\hline Presence of cavities & 40.85 & 2.02 to 825.02 & 0.016 \\
\hline \multicolumn{4}{|l|}{ Index case smear result } \\
\hline Negative & Ref & & \\
\hline$<++$ & 2.49 & 0.49 to 12.74 & 0.273 \\
\hline$++/+++$ & 4.85 & 1.35 to 17.45 & 0.015 \\
\hline $\begin{array}{l}\text { Child sleeps in the same house as index } \\
\text { case }\end{array}$ & 5.50 & 1.28 to 23.67 & 0.022 \\
\hline TST done previously & 3.64 & 1.08 to 12.28 & 0.037 \\
\hline Interaction contact age $\times$ cavities & 0.03 & 0.00 to 1.19 & 0.062 \\
\hline \multicolumn{4}{|l|}{ Absence of cavities } \\
\hline Contact age $<5$ & Ref & & \\
\hline Contact age $>5$ & 60.39 & 1.80 to 2023.06 & 0.022 \\
\hline \multicolumn{4}{|l|}{ Presence of cavities } \\
\hline Contact age $<5$ & Ref & & \\
\hline Contact age $>5$ & 1.86 & 0.45 to 7.68 & 0.390 \\
\hline
\end{tabular}

aOR, adjusted OR; LTBI, latent tuberculosis infection; ref, reference; TST, tuberculin skin test.

p-values $<0.005$ in bold. 


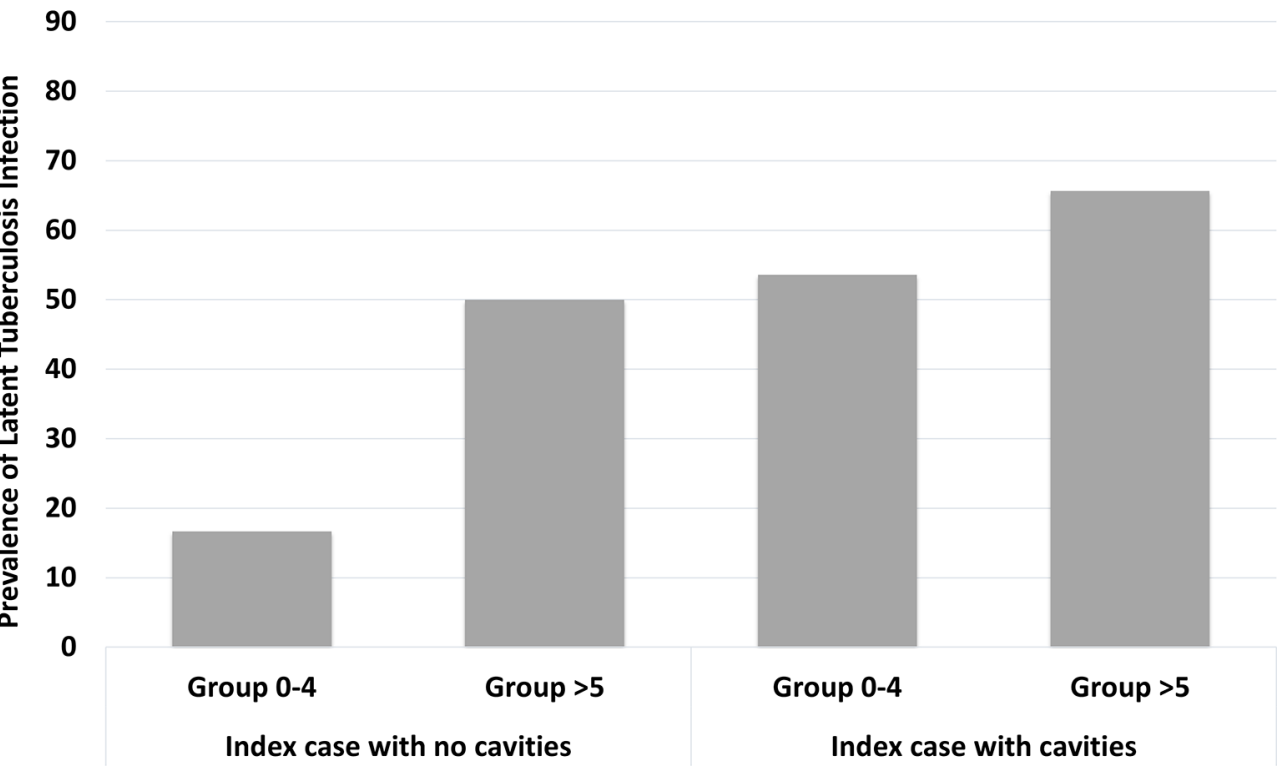

Figure 2 Prevalence of latent tuberculosis infection by age group and presence of lung cavities in the index case.

among the closest contacts (ie, sleeping in the same house as the index case) and in households with a high density of residents. Although the odds of infection in contacts of smear-positive patients were more than three times higher than those of contacts of smear-negative patients, the infectiousness of smear-negative patients was not negligible considering that $36 \%$ of their contacts were infected. In addition, we found an interesting interaction between the age of the contact and the presence of cavities in the index case. In the absence of cavities, children $>5$ years had a higher risk of infection, possibly explained by the higher cumulative risk. Some children may have been infected previously, not necessarily by the study index case. However, this age-related risk disappeared in patients with cavities, suggesting that the higher infectiousness due to the cavities equalised the risk among younger and older children.

This study has several limitations. First, we had to rely on the index case for the identification of paediatric contacts; therefore, we may have missed non-reported contacts, which may have influenced our estimated infection and disease rates. To reduce this risk, the contacts' information was cross-validated with the contact-tracing files from the TB services. Second, some children had a missing TST or IGRA result at the initial evaluation. To address this, we performed additional statistical analyses that confirmed our main findings. Third, our study was not powered to measure the prevalence of $\mathrm{TB}$ disease; therefore, a higher prevalence than the observed cannot be excluded. Also, although unlikely, we cannot rule out that some children lost to follow-up developed TB disease and received healthcare elsewhere.

Preventive treatment for patients infected with a drug-susceptible strain has been proven to be an effective intervention to prevent TB disease. ${ }^{126}$ While we wait for the results of ongoing international clinical trials of LTBI regimens in contacts of patients with DR-TB (TB CHAMP (Tuberculosis child multidrug-resistant preventive therapy); V-QUIN (levofloxacin for the prevention of tuberculosis among household contacts of patients; PHOENIx (Protecting Households On Exposure to Newly Diagnosed Index Multidrug-Resistant Tuberculosis Patients)), WHO recommends that preventive treatment be considered for children who are household contacts, based on an individual risk assessment and sound clinical justification. ${ }^{1}$ Although our study was not specifically powered to address this, the nil incidence of TB disease in our cohort suggests that in Armenia individualised risk assessment for DR-TB preventive therapy should be done. Nevertheless, the prevalence of TB disease was not negligible, and screening for symptoms of TB disease in child contacts of patients with DR-TB appears crucial, together with follow-up, and repeated testing of non-infected contacts. In addition, our data confirm that priority should be given to the investigation of children in close contact with patients with DR-TB and to children in contact with highly contagious patients, such as those with lung cavities or sputum smear-positive results.

Acknowledgements We would like to thank Dr Carlos Perez Velez, Dr Marc Tebruegge, Dr Tom Connell, Dr Norma Edith Gonzalez and Dr Mercedes Becerra, members of the Scientific Committee of this research study, for their technical support. We acknowledge the continuous support from the National Tuberculosis Program in Armenia. We also thank the doctors, nurses, counsellors and other staff taking care of patients diagnosed and treated for tuberculosis in Armenia and of their paediatric contacts. Without their collaboration this study would have not been possible. We would like to thank the MSF staff in Armenia and in the headquarters for their work and support throughout the study, particularly Mariane Gale and Jamil Faqirzai. Most importantly, we would like to thank the children, their parents and legal guardians for kindly participating in this study.

Contributors HH and ES-P conceptualised and designed the study, coordinated and supervised data collection, drafted the initial manuscript, and reviewed and revised the manuscript. NM and HA collaborated in designing the data collection instruments, interviewed and evaluated the patients, collected the data, and reviewed and revised the manuscript. MBa performed the initial analyses and reviewed and revised the manuscript. CH participated in the study conception and design and interpretation of data, and reviewed and revised the manuscript. $\mathrm{AH}$, $\mathrm{AU}, \mathrm{NK}$ and FV participated in the study conception and design, and interpretation of data. MBo conceptualised and designed the study and critically reviewed the manuscript for important intellectual content. All authors approved the final manuscript as submitted and agree to be accountable for all aspects of the work.

Funding This study was funded by Médecins Sans Frontières-France.

Competing interests None declared.

Patient consent for publication Obtained.

Ethics approval Ethics approval was obtained from the Comité Consultatif de Protection des Personnes dans la Recherche Médicale in Saint-Germain-en-Laye (France) and from the ethical review board of the Medical University of Yerevan (Armenia). 
Provenance and peer review Not commissioned; externally peer reviewed.

Open access This is an open access article distributed in accordance with the Creative Commons Attribution Non Commercial (CC BY-NC 4.0) license, which permits others to distribute, remix, adapt, build upon this work non-commercially, and license their derivative works on different terms, provided the original work is properly cited, appropriate credit is given, any changes made indicated, and the use is non-commercial. See: http://creativecommons.org/licenses/by-nc/4.0/.

\section{REFERENCES}

1 World Health Organization. Latent tuberculosis infection: updated and consolidated guidelines for programmatic management. Geneva 2018.

2 Yang C, Luo T, Shen X, et al. Transmission of multidrug-resistant Mycobacterium tuberculosis in Shanghai, China: a retrospective observational study using whole-genome sequencing and epidemiological investigation. Lancet Infect Dis 2017; 17:275-84.

3 Liu Q, Zuo T, Xu P, et al. Have compensatory mutations facilitated the current epidemic of multidrug-resistant tuberculosis? Emerg Microbes Infect 2018;7:98.

4 Blower SM, Chou T. Modeling the emergence of the 'hot zones': tuberculosis and the amplification dynamics of drug resistance. Nat Med 2004;10:1111-6.

5 Schaaf HS, Gie RP, Kennedy M, et al. Evaluation of young children in contact with adult multidrug-resistant pulmonary tuberculosis: a 30-month follow-up. Pediatrics 2002;109:765-71.

6 Seddon JA, Hesseling AC, Finlayson H, et al. Preventive therapy for child contacts of multidrug-resistant tuberculosis: a prospective cohort study. Clin Infect Dis 2013;57:1676-84.

7 Amanullah $F$, Ashfaq M, Khowaja S, et al. High tuberculosis prevalence in children exposed at home to drug-resistant tuberculosis. Int J Tuberc Lung Dis 2014;18:520-7.

8 Becerra MC, Franke MF, Appleton SC, et al. Tuberculosis in children exposed at home to multidrug-resistant tuberculosis. Pediatr Infect Dis J 2013:32:115-9.

9 Seddon JA, Hesseling AC, Godfrey-Faussett P, et al. Risk factors for infection and disease in child contacts of multidrug-resistant tuberculosis: a cross-sectional study. BMC Infect Dis 2013;13:392.

10 Laniado-Laborín R, Cazares-Adame R, Volker-Soberanes ML, et al. Latent tuberculous infection prevalence among paediatric contacts of drug-resistant and drug-susceptible cases. Int J Tuberc Lung Dis 2014;18:515-9.

11 Salazar-Vergara RM, Sia IG, Tupasi TE, et al. Tuberculosis infection and disease in children living in households of Filipino patients with tuberculosis: a preliminary report. Int J Tuberc Lung Dis 2003;7:S494-500.
12 World Health Organization. Global Tuberculosis Report. Geneva: World Health Organization, 2017

13 Handbook for district hospitals in resource constrained setings on quality assurance of chest radiography: for better TB control and health system strengthening. http://www. tbcare1.org/publications/toolbox/tools/access/XRayQAHandbook.pdf (Accessed 15 Dec 2017).

14 Graham SM, Ahmed T, Amanullah F, et al. Evaluation of tuberculosis diagnostics in children: 1. Proposed clinical case definitions for classification of intrathoracic tuberculosis disease. Consensus from an expert panel. J Infect Dis 2012;205:S199-208.

15 Mendrekar JN, Mandrekar SJ, Cha SS. Cutpoint Determination Methods in Survival Analysis Using SAS. Stat Data Anal 2002:1-5.

16 Corbett EL, Watt CJ, Walker N, et al. The Growing Burden of Tuberculosis. Arch Intern Med 2003;163:1009.

17 Cegielski JP, McMurray DN. The relationship between malnutrition and tuberculosis: evidence from studies in humans and experimental animals. Int J Tuberc Lung Dis 2004:8:286-98.

18 Marais BJ, Gie RP, Schaaf HS, et al. The clinical epidemiology of childhood pulmonary tuberculosis : a critical review of literature from the pre-chemotherapy era. 2004;8:278-85.

19 UNAIDS/WHO Epidemiological Fact Sheet: Armenia- 2016 Update. http://www. unaids.org/en/regionscountries/countries/armenia (Accessed 13 Dec 2017).

20 Marais BJ, Gie RP, Schaaf HS, et al. The natural history of childhood intra-thoracic tuberculosis: a critical review of literature from the pre-chemotherapy era. Int I Tuberc Lung Dis 2004;8:392-402

21 Burgos M, DeRiemer K, Small PM, et al. Effect of drug resistance on the generation of secondary cases of tuberculosis. J Infect Dis 2003;188:1878-84.

22 Golla V, Snow K, Mandalakas AM, et al. The impact of drug resistance on the risk of tuberculosis infection and disease in child household contacts: a cross sectional study. BMC Infect Dis 2017:17:593.

23 Müller B, Borrell S, Rose G, et al. The heterogeneous evolution of multidrug-resistant Mycobacterium tuberculosis. Trends Genet 2013;29:160-9.

24 Gagneux S. Fitness cost of drug resistance in Mycobacterium tuberculosis. Clin Microbiol Infect 2009;15:66-8.

25 Grandjean L, Gilman RH, Martin L, et al. Transmission of multidrug-resistant and drugsusceptible tuberculosis within households: a prospective cohort study. PLoS Med 2015;12:e1001843.

26 Getahun H, Matteelli A, Chaisson RE, et al. Latent Mycobacterium tuberculosis infection. N Eng/ J Med 2015;372:2127-35. 